\title{
REFLEXO DO SERVIÇO NOTURNO FRENTE ÀS CONDIÇÕES DE TRABALHO, SAÚDE, VIDA SOCIAL E FAMILIAR DO PROFISSIONAL DE ENFERMAGEM
}

Front night service reflex to working conditions, health, social and family life of nursing professional

Claudemir Santos de Jesus ${ }^{1}$, Carlos Eduardo Gomes Marinho², Cintia Ferreira Soares $^{3}$, Edvania Soares da Silva ${ }^{4}$, Valéria Seabra Ferreira ${ }^{5}$

${ }^{1}$ Enfermeiro, Mestre em Enfermagem pela EEAN/UFRJ, Professor Convidado pela Universidade Veiga de Almeida.

2 Enfermeiro, Especialista em Enfermagem do trabalho pela Universidade Veiga de Almeida.

${ }^{3}$ Enfermeira pela Faculdade de Duque de Caxias - UNIESP.

${ }^{4}$ Enfermeira, Coordenadora da Pós-graduação em Enfermagem do Trabalho pela Universidade Veiga de Almeida.

${ }^{5}$ Enfermeira pela Faculdade de Duque de Caxias - UNIESP

\section{Endereço para correspondência:}

Claudemir Santos de Jesus

Rua São Francisco Xavier, 859, Apt. 1002, BI. A, Maracanã, Rio de Janeiro-RJ.

Telefone: (21) 96487-0169.

Email: udemi34@yahoo.com.br 


\title{
Resumo
}

O estudo em tela teve como objetivo identificar os resultados das condições de trabalho noturno frente à saúde, vida social e familiar do profissional de Enfermagem. Trata-se de revisão integrativa, com abordagem quantitativa, com a questão de pesquisa: Quais os resultados das condições de trabalho noturno frente à saúde, vida social e familiar do profissional de Enfermagem? A busca foi realizada na Biblioteca Virtual de Saúde, nas bases de dados: LILACS, BDENF, com o resultado de 06 artigos. Na discussão, foi apontada a necessidade de refletir frente aos resultados das condições de trabalho noturno na saúde, vida social e familiar do profissional de Enfermagem. Ao concluir, ficou evidente que os transtornos na vida social e familiar e os agravos à saúde dos membros da equipe de Enfermagem são evitáveis a partir do momento que haja adequações no ambiente laboral, os direitos trabalhistas sejam respeitados, como também a aprovação das lutas da profissão de Enfermagem, fica claro que o bem estar físico e psicológico será preservado.

Palavras-chave: Trabalho Noturno; Enfermagem do Trabalho; Saúde do Trabalhador.

\begin{abstract}
The study screen aimed to identify the results of working conditions night against the health, social and family life of nursing professionals. This is an integrative review, with a quantitative approach to the research question: What are the results of the night working conditions across the health, social and family life of nursing professionals? The search was conducted in the Virtual Health Library, in databases: LILACS, BDENF, with the result of 06 articles. In the discussion, the need to reflect forward the results of night work conditions in health, social and family life of nursing professionals was appointed. When finished, it become clear that the disruption in social and family life and the health problems of members of the nursing staff are evitais from the moment that there are adjustments in the work environment, labor rights are respected, as well as the approval of the nursing profession struggles, it is clear that the physical well-being and psychological will be preserved.
\end{abstract}

Keywords: Night Work; Ocupational Health Nursing; Ocupacional Health. 
A preocupação com trabalho noturno é um interesse crescente, explorado em estudos por profissionais de diversas áreas, que reflete no atendimento eficaz às demandas para o funcionamento e manutenção dos serviços de saúde oferecidos.

O serviço noturno se torna mais frequente e a tendência conduz o trabalhador ao desenvolvimento de atividades laborais nesse turno, que pela legislação brasileira ocorre a partir das 22 horas até, pelo menos, às 5 horas do dia seguinte ${ }^{1}$.

Esse estudo emergiu das observações da prática de vinte e seis anos no serviço noturno, cujos profissionais de Enfermagem, equipe multidisciplinar e de outras áreas, sofrem situações adversas em relação ao impacto fisiológico.

Os estudos evidenciam que no trabalho noturno há sintomatologia de fadiga, cansaço e/ou sonolência diurna excessiva, o que emerge um impacto social, por causa das dificuldades nas relações entre a vida pessoal e a jornada de trabalho dos profissionais de Enfermagem, envolvendo histórias de conflitos, dificuldades de conciliação, harmonia na vida conjugal, prejuízos na comunicação entre pais-filhos e tarefas domésticas rotineiras ${ }^{1}$.

Porém, há existência de resultados positivos do trabalho noturno, como melhor remuneração, com adicional noturno, tempo para atividades cotidianas, qualificações, atualizações durante o dia, prática de esportes e cuidados de familiares em processo de manutenção da saúde nos casos de adoecimento².

Ao apontar estas situações, traçamos como objeto: os resultados das condições de trabalho noturno frente à saúde, vida social e familiar do profissional de Enfermagem. Assim, ao deparar com o serviço de Enfermagem, as tarefas englobam turnos diurnos, noturnos ou rotatórios, geralmente de 08 a 12 horas de duração por plantão ou diária em regimes de 30 ou 40 horas semanais, requerendo por muitas vezes a reorganização do trabalhador ${ }^{1}$.

Para esse, o trabalho noturno tem efeitos diretos e indiretos sobre o organismo e na vida pessoal, visto que as atividades laborais no sentido inverso ao funcionamento fisiológico podem levar a alterações do desempenho, diferente do horário diurno, que facilita para a produção e funcionamento contínuo do serviço².

Ao visar às contribuições para o ensino de graduação, pós-graduação, extensão universitária e laboral, identifica-se no estudo os resultados 


\section{Atenção à Saúde}

predominantemente negativos causados pelo serviço noturno voltados pelas condições trabalhistas, com aproximação das lutas nacionais pelo sistema COREN/COFEN, Sindicatos e políticos, o que aponta para uma oportunidade de refletir os problemas e soluções, em relação à manutenção da saúde, vida social e familiar, no cotidiano dos profissionais de Enfermagem.

O que reporta à relevância da pesquisa, com vistas ao conhecimento e reflexão dos resultados das condições de trabalho noturno frente à saúde, vida social e familiar do profissional de Enfermagem. Neste caso, a produção de conhecimento nesta área permitirá os sustentáculos que irão fortalecer e apoiar intervenções direcionadas e individualizadas dos trabalhadores de enfermagem, facilitando o ensino e a pesquisa, além de permitir comparações específicas entre grupos de trabalhadores em diversos cenários ${ }^{3}$.

Mediante ao escrito, objetivamos identificar os resultados das condições de trabalho noturno frente à saúde, vida social e familiar do profissional de Enfermagem.

\section{METODOLOGIA E RESULTADOS}

Este estudo de revisão integrativa tem o intuito de verificar as publicações relacionadas ao tema, para evidenciar o conhecimento no campo científico, através das seis etapas compreendidas pela metodologia proposta ${ }^{4}$.

A primeira etapa foi constatada pela questão de pesquisa: Quais os resultados das condições de trabalho noturno frente à saúde, vida social e familiar do profissional de Enfermagem?

Na segunda etapa houve a busca no site da Biblioteca Virtual de Saúde (BVS), nas bases de dados LILACS, BDENF - Enfermagem, com os critérios de inclusão: artigos disponíveis em português, para evidenciar o tema em território nacional brasileiro, no período de 2006 a 2014, com assunto principal Trabalho Noturno e os descritores: "Trabalho Noturno" and "Enfermagem do Trabalho" and "Saúde do Trabalhador" .

$\mathrm{Na}$ BVS, frente aos descritores "Trabalho Noturno" and "Enfermagem do Trabalho" and "Saúde do Trabalhador", foram encontrados 62 artigos, dos quais 15 foram adequados aos critérios de inclusão e exclusão, sendo selecionado 01. Nos 


\section{Atenção à Saúde}

descritores "Trabalho Noturno" and "Enfermagem do Trabalho", evidenciamos 144 estudos, que no filtro foram coletados 32 , tendo aderência ao tema 02 .

Quadro 1. Cruzamento dos descritores.

\begin{tabular}{|c|c|c|c|c|c|c|c|c|c|c|c|c|}
\hline DESCRITORES & TOTAL & 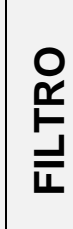 & 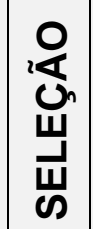 & ๕్ & ڤ્̀ & 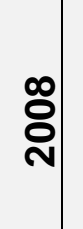 & : & 을 & ז' & พั & $\stackrel{m}{\alpha}^{\frac{m}{n}}$ & 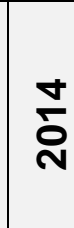 \\
\hline $\begin{array}{l}\text { Trabalho Noturno and } \\
\text { Enfermagem do Trabalho and } \\
\text { Saúde do Trabalhador }\end{array}$ & 62 & 15 & 01 & 0 & 0 & 0 & 0 & 0 & 01 & 0 & 0 & 0 \\
\hline $\begin{array}{l}\text { Trabalho Noturno and } \\
\text { Enfermagem do Trabalho }\end{array}$ & 144 & 32 & 02 & 01 & 0 & 0 & 0 & 0 & 01 & 0 & 0 & 0 \\
\hline $\begin{array}{l}\text { Trabalho Noturno and Saúde do } \\
\text { Trabalhador }\end{array}$ & 122 & 21 & 02 & 0 & 0 & 0 & 0 & 0 & 01 & 01 & 0 & 0 \\
\hline $\begin{array}{l}\text { Enfermagem do Trabalho and } \\
\text { Saúde do Trabalhador }\end{array}$ & 8.920 & 06 & 02 & 0 & 0 & 0 & 01 & 01 & 0 & 0 & 0 & 0 \\
\hline TOTAL & 9.248 & 74 & 06 & 01 & 0 & 0 & 01 & 01 & 02 & 01 & 0 & 0 \\
\hline
\end{tabular}

Mas ao cruzar "Trabalho Noturno" and "Saúde do Trabalhador", das 122 produções, filtrou-se 21 e selecionou-se 02. Porém ao cruzar os descritores Enfermagem do Trabalho and Saúde do Trabalhador, teve-se como resultado 8.920 produtos, que ao incluir o assunto principal: Trabalho noturno, e o limite: Humanos, Adulto, foi evidenciado 05, dos quais selecionou-se 02.

Assim, dos 9.248 , com os critérios tivemos 74 , onde percebemos que várias publicações eram evidenciadas em mais de uma base de dados, o que resultou em 06 produções relacionadas ao tema.

$\mathrm{Na}$ terceira etapa um instrumento de coleta de dados foi utilizado para extrair as informações chaves de cada artigo selecionado, observando-se a base de dados, ano, local de publicação, título, tipo de pesquisa e de produção, evidenciando os resultados (quadro 02$)^{5}$. 
Quadro 02. Resultado da Coleta de Dados dos Artigos na BVS.

\begin{tabular}{|c|c|c|c|c|c|c|c|c|}
\hline Periódico & $\begin{array}{c}\text { Qualis } \\
2014\end{array}$ & Base & Ano & Local & Autor & Título & $\begin{array}{l}\text { Tipo de } \\
\text { Pesquisa }\end{array}$ & $\begin{array}{c}\text { Tipo de } \\
\text { Produção }\end{array}$ \\
\hline $\begin{array}{l}\text { Cuidado é } \\
\text { Fundamental } \\
\text { Online }\end{array}$ & B2 & BDENF & 2012 & RJ & $\begin{array}{l}\text { SILVA, } \\
\text { FONTANA, } \\
\text { ALMEIDA. }\end{array}$ & $\begin{array}{l}\text { Diagnósticos de } \\
\text { Enfermagem na } \\
\text { saúde do } \\
\text { trabalhador: } \\
\text { estudo de caso } \\
\text { com profissionais } \\
\text { de Enfermagem }\end{array}$ & $\begin{array}{l}\text { Qualitativa, } \\
\text { estudo de } \\
\text { caso }\end{array}$ & $\begin{array}{l}\text { Artigo } \\
\text { Original }\end{array}$ \\
\hline $\begin{array}{c}\text { Esc Anna } \\
\text { Nery }\end{array}$ & B1 & BDENF & $=2011$ & RJ & SILVA et al. & $\begin{array}{l}\text { Trabalho noturno } \\
\text { e a repercussão } \\
\text { na saúde dos } \\
\text { Enfermeiros }\end{array}$ & $\begin{array}{l}\text { Qualitativa, } \\
\text { de campo, } \\
\text { descritiva }\end{array}$ & $\begin{array}{l}\text { Artigo } \\
\text { Original }\end{array}$ \\
\hline $\begin{array}{c}\text { Esc Anna } \\
\text { Nery }\end{array}$ & B1 & LILACS & 2011 & RS & SILVA et al. & $\begin{array}{c}\text { Sentido do } \\
\text { trabalho para } \\
\text { Enfermeiros } \\
\text { noturnos de um } \\
\text { Hospital } \\
\text { Universitário: } \\
\text { estudo descritivo }\end{array}$ & $\begin{array}{c}\text { Qualitativa, } \\
\text { exploratória } \\
\text { descritiva }\end{array}$ & $\begin{array}{l}\text { Artigo } \\
\text { Original }\end{array}$ \\
\hline $\begin{array}{l}\text { Rev. } \\
\text { Enferm. } \\
\text { UERJ }\end{array}$ & B1 & BDENF & $=2010$ & RJ & NEVES et al. & $\begin{array}{c}\text { Influência do } \\
\text { trabalho noturno } \\
\text { na qualidade de } \\
\text { vida do } \\
\text { Enfermeiro }\end{array}$ & $\begin{array}{c}\text { Abordagem } \\
\text { qualitativa }\end{array}$ & $\begin{array}{l}\text { Artigo } \\
\text { Original }\end{array}$ \\
\hline $\begin{array}{l}\text { Cogitare } \\
\text { Enferm }\end{array}$ & B2 & BDENF & 2009 & PR & $\begin{array}{c}\text { MAYNARDES } \\
\text {, SARQUIS, } \\
\text { KIRCHHOF. }\end{array}$ & $\begin{array}{l}\text { Trabalho noturno } \\
\text { e morbidades de } \\
\text { trabalhadores de } \\
\text { Enfermagem }\end{array}$ & $\begin{array}{c}\text { Qualitativa, } \\
\text { exploratória } \\
\text { descritiva }\end{array}$ & $\begin{array}{l}\text { Artigo } \\
\text { Original }\end{array}$ \\
\hline $\begin{array}{c}\text { Esc Anna } \\
\text { Nery }\end{array}$ & B1 & BDENF & 2006 & RJ & $\begin{array}{l}\text { LISBOA, } \\
\text { OLIVEIRA, } \\
\text { REIS. }\end{array}$ & $\begin{array}{c}\text { O trabalho } \\
\text { noturno e a } \\
\text { prática de } \\
\text { Enfermagem: } \\
\text { uma percepção } \\
\text { dos estudantes } \\
\text { de Enfermagem }\end{array}$ & $\begin{array}{l}\text { Abordagem } \\
\text { quantitativa }\end{array}$ & $\begin{array}{l}\text { Artigo } \\
\text { Original }\end{array}$ \\
\hline
\end{tabular}

Relacionado ao recorte temporal de 2005 a 2015, ao evidenciar 06 artigos em português, relacionados à temática do estudo, destes percebe-se que no ano de 2005 não houve produção com o tema, mas os anos de 2006, 2009, 2010 e 2012 apresentaram apenas 01 publicação por ano e em 201102 publicações.

Ao tipo de pesquisa do recorte temporal, foram evidenciadas: Qualitativa, de campo, descritiva (01); Qualitativa, estudo de caso (01); Abordagem qualitativa (02); Qualitativa exploratória descritiva (02). 
Relacionado ao tipo de instrumento de coleta de dados, os 06 artigos foram pesquisados com periódico na íntegra. Quanto aos periódicos, foram identificados 03 na Escola de Enfermagem Ana Nery (Qualis B1) e 01 da Cuidado é Fundamental Online (C), Rev. Enferm. UERJ (B1) e Cogitare Enferm (B2). Relacionado ao sujeito da pesquisa, os 06 artigos tiveram como sujeitos os profissionais de Enfermagem.

$\mathrm{Na}$ quarta etapa, os artigos que foram selecionados para revisão integrativa foram analisados para a verificação de sua autenticidade, qualidade metodológica, importância das informações e representatividade. Por esta razão o quadro 03 foi construído para realizar o agrupamento dos dados à luz da análise temática ${ }^{4,5}$.

Quadro 03. Instrumento de Análise das Temáticas do Estudo.

\begin{tabular}{|c|c|c|c|c|}
\hline \multicolumn{5}{|c|}{ TEMÁTICAS DO ESTUDO } \\
\hline $\begin{array}{l}\text { Unidade } \\
\text { Temática }\end{array}$ & Categoria & Título & Objetivo & Dados Evidenciados \\
\hline \multirow{3}{*}{$\begin{array}{c}\text { Trabalho } \\
\text { noturno frente } \\
\text { às doenças } \\
\text { ocupacionais } \\
\text { e a qualidade } \\
\text { de vida dos } \\
\text { profissionais } \\
\text { de } \\
\text { Enfermagem }\end{array}$} & \multirow{3}{*}{$\begin{array}{c}\text { As } \\
\text { consequências } \\
\text { ocupacionais } \\
\text { do trabalho } \\
\text { noturno e a } \\
\text { qualidade de } \\
\text { vida dos } \\
\text { profissionais de } \\
\text { Enfermagem }\end{array}$} & $\begin{array}{l}\text { Trabalho } \\
\text { noturno e a } \\
\text { repercussão na } \\
\text { saúde dos } \\
\text { Enfermeiros }\end{array}$ & $\begin{array}{l}\text { Apresentar e discutir } \\
\text { as alterações na } \\
\text { saúde percebidas por } \\
\text { enfermeiros do } \\
\text { período noturno }\end{array}$ & $\begin{array}{c}\text { Evidenciou que é } \\
\text { necessária a } \\
\text { compreensão do } \\
\text { trabalhador sobre os } \\
\text { limites do seu corpo } \\
\text { para que a realização } \\
\text { da atividade não } \\
\text { interfira no processo } \\
\text { saúde-doença e não } \\
\text { comprometa a } \\
\text { assistência prestada. }\end{array}$ \\
\hline & & $\begin{array}{c}\text { Diagnósticos } \\
\text { de } \\
\text { Enfermagem } \\
\text { na saúde do } \\
\text { trabalhador: } \\
\text { Estudo de caso } \\
\text { com } \\
\text { profissionais } \\
\text { de } \\
\text { Enfermagem }\end{array}$ & $\begin{array}{c}\text { Identificar } \\
\text { Diagnósticos de } \\
\text { enfermagem da } \\
\text { NANDA } \\
\text { Internacional } \\
\text { relacionados ao } \\
\text { trabalho de } \\
\text { auxiliares e } \\
\text { técnicos de } \\
\text { enfermagem que } \\
\text { atuam no turno da } \\
\text { noite nas unidades } \\
\text { de enfermagem } \\
\text { clínica e cirúrgica } \\
\text { de uma instituição } \\
\text { hospitalar }\end{array}$ & $\begin{array}{c}\text { Mostrou que os } \\
\text { trabalhadores } \\
\text { apresentaram Risco de } \\
\text { infecção, Risco de } \\
\text { lesão (física), Risco de } \\
\text { lesão (química), Risco } \\
\text { de resposta alérgica ao } \\
\text { látex, Disposição para } \\
\text { autoconceito } \\
\text { melhorado e Risco de } \\
\text { tensão de papel de } \\
\text { cuidador. }\end{array}$ \\
\hline & & $\begin{array}{l}\text { Influência do } \\
\text { trabalho }\end{array}$ & $\begin{array}{l}\text { Investigar a } \\
\text { influência do }\end{array}$ & $\begin{array}{l}\text { Indicou uma relação } \\
\text { entre a capacidade }\end{array}$ \\
\hline
\end{tabular}




\begin{tabular}{|c|c|c|c|c|}
\hline \multicolumn{5}{|c|}{ TEMÁTICAS DO ESTUDO } \\
\hline $\begin{array}{l}\text { Unidade } \\
\text { Temática }\end{array}$ & Categoria & Título & Objetivo & Dados Evidenciados \\
\hline & & $\begin{array}{l}\text { noturno na } \\
\text { qualidade de } \\
\text { vida do } \\
\text { Enfermeiro }\end{array}$ & $\begin{array}{c}\text { trabalho noturno na } \\
\text { qualidade de vida } \\
\text { do enfermeiro, bem } \\
\text { como sua } \\
\text { concepção sobre } \\
\text { qualidade de vida }\end{array}$ & $\begin{array}{c}\text { para o trabalho e a } \\
\text { qualidade de vida, a } \\
\text { partir do atendimento } \\
\text { de necessidades } \\
\text { básicas como saúde, } \\
\text { moradia, lazer, trabalho } \\
\text { e remuneração digna }\end{array}$ \\
\hline & & $\begin{array}{c}\text { O trabalho } \\
\text { noturno e a } \\
\text { prática de } \\
\text { Enfermagem: } \\
\text { uma percepção } \\
\text { dos estudantes } \\
\text { de } \\
\text { Enfermagem }\end{array}$ & $\begin{array}{c}\text { Identificar a } \\
\text { percepção do } \\
\text { acadêmico de } \\
\text { enfermagem sobre } \\
\text { a influência do } \\
\text { plantão noturno na } \\
\text { saúde do } \\
\text { trabalhador de } \\
\text { enfermagem }\end{array}$ & $\begin{array}{l}\text { Embora poucos } \\
\text { acadêmicos de } \\
\text { enfermagem tenham } \\
\text { tido a experiência com } \\
\text { o trabalho noturno, a } \\
\text { maioria conhece } \\
\text { alguns efeitos } \\
\text { negativos que podem } \\
\text { ser ocasionados, } \\
\text { porém associaram aos } \\
\text { aspectos fisiológicos. }\end{array}$ \\
\hline & & $\begin{array}{c}\text { Trabalho } \\
\text { noturno e } \\
\text { morbidades de } \\
\text { trabalhadores } \\
\text { de } \\
\text { Enfermagem }\end{array}$ & $\begin{array}{l}\text { Identificar os } \\
\text { principais agravos } \\
\text { à saúde desses } \\
\text { trabalhadores }\end{array}$ & $\begin{array}{c}\text { As consequências } \\
\text { acarretadas à saúde } \\
\text { são apontadas como } \\
\text { um grande problema e } \\
\text { medidas de } \\
\text { intervenção devem ser } \\
\text { estudadas para o } \\
\text { processo saúde } \\
\text { doença dos } \\
\text { trabalhadores. }\end{array}$ \\
\hline & & $\begin{array}{l}\text { Sentido do } \\
\text { trabalho para } \\
\text { Enfermeiros } \\
\text { noturnos de } \\
\text { um hospital } \\
\text { universitário: } \\
\text { Sentido do } \\
\text { estudo } \\
\text { descritivo }\end{array}$ & $\begin{array}{c}\text { Identificar o sentido } \\
\text { do trabalho } \\
\text { atribuído pelos } \\
\text { enfermeiros que } \\
\text { atuam no período } \\
\text { noturno, } \\
\text { relacionando-o à } \\
\text { satisfação ou } \\
\text { insatisfação } \\
\text { profissional }\end{array}$ & $\begin{array}{c}\text { Revelou o sentido dos } \\
\text { gestores criar e } \\
\text { implementar } \\
\text { estratégias que } \\
\text { permitam ampliar } \\
\text { ações referentes à } \\
\text { saúde do trabalhador } \\
\text { na perspectiva da } \\
\text { melhoria dos serviços e } \\
\text { da satisfação } \\
\text { profissional. }\end{array}$ \\
\hline
\end{tabular}

Os estudos acima evidenciaram que o delineamento da pesquisa para a análise foi baseada no nível 4: evidências de estudos descritivos (não experimentais) ou com abordagem qualitativa ${ }^{4}$. 
$\mathrm{Na}$ qual podemos observar a escassez de estudos a partir da sistematização dos descritores, o que remeteu à Unidade Temática: Trabalho Noturno frente às doenças ocupacionais e a qualidade de vida dos profissionais de Enfermagem, com a categoria única: As consequências ocupacionais do trabalho noturno e a qualidade de vida dos profissionais de Enfermagem.

Dessa forma, a quinta etapa consistiu da interpretação e discussão dos dados e resultados encontrados que estavam relacionados ao trabalho noturno do profissional de Enfermagem, pela metodologia análise de temática, ao emergir o tema: Trabalho noturno frente às doenças ocupacionais e a qualidade de vida dos profissionais de Enfermagem ${ }^{6}$.

Porém, mediante toda a busca, observamos a necessidade de buscar mais produções fora dos critérios de inclusão e exclusão, para fundamentar a discussão e validar as informações dos artigos captados na revisão integrativa (quadro 04).

Quadro 04. Artigos de Suporte para a Discussão dos Dados.

\begin{tabular}{|c|c|c|c|c|}
\hline $\begin{array}{c}\text { Referência } \\
\text { no texto }\end{array}$ & Ano & Periódicos & Título & $\begin{array}{l}\text { Tipo de } \\
\text { Produção }\end{array}$ \\
\hline 1 & 2003 & Atheneu Rio & $\begin{array}{c}\text { Trabalho em Turnos e Noturno: } \mathrm{Na} \\
\text { Sociedade } 24 \text { Horas }\end{array}$ & Livro \\
\hline 7 & 2009 & $\begin{array}{l}\text { Rev. Gaúcha } \\
\text { de } \\
\text { Enfermagem }\end{array}$ & $\begin{array}{c}\text { Possibilidades e limites da recuperação } \\
\text { do sono de trabalhadores de } \\
\text { enfermagem }\end{array}$ & Artigo \\
\hline 10 & 2008 & Einstein & \begin{tabular}{|c|} 
Avaliação do padrão do sono dos \\
profissionais de enfermagem dos \\
plantões noturnos em Unidade de \\
Terapia Intensiva. São Paulo \\
\end{tabular} & Artigo \\
\hline 11 & 2001 & $\begin{array}{l}\text { Cad. Saúde } \\
\text { Pública }\end{array}$ & $\begin{array}{c}\text { Gênero e trabalho noturno: sono, } \\
\text { cotidiano e vivências de quem troca a } \\
\text { noite pelo dia }\end{array}$ & Artigo \\
\hline 13 & 2003 & $\begin{array}{l}\text { São Paulo em } \\
\text { Perspectiva }\end{array}$ & $\begin{array}{l}\text { A saúde do trabalhador na sociedade } \\
24 \text { horas }\end{array}$ & Artigo \\
\hline 14 & 2008 & $\begin{array}{l}\text { Estudos de } \\
\text { Psicologia }\end{array}$ & $\begin{array}{c}\text { Trabalho noturno e o novo papel } \\
\text { paterno: uma interface difícil }\end{array}$ & Artigo \\
\hline 15 & 2010 & $\begin{array}{l}\text { Rev. Latino- } \\
\text { Am. } \\
\text { Enfermagem }\end{array}$ & $\begin{array}{c}\text { O trabalho em turnos alternados e seus } \\
\text { efeitos no cotidiano do trabalhador no } \\
\text { beneficiamento de grãos }\end{array}$ & Artigo \\
\hline 17 & 2007 & $\begin{array}{l}\text { J. Bras. } \\
\text { Psiquiatr. }\end{array}$ & $\begin{array}{c}\text { Sonolência diurna excessiva em } \\
\text { trabalhadores da área de enfermagem }\end{array}$ & Artigo \\
\hline 18 & 2009 & $\begin{array}{l}\text { Universidade } \\
\text { Federal de } \\
\text { Minas Gerais }\end{array}$ & $\begin{array}{l}\text { Agravos a saúde do trabalhador da } \\
\text { área de saúde, com ênfase nas }\end{array}$ & Monografia \\
\hline
\end{tabular}




\section{Atenção à Saúde}

\begin{tabular}{|c|c|c|c|c|}
\hline $\begin{array}{c}\text { Referência } \\
\text { no texto }\end{array}$ & Ano & Periódicos & Título & $\begin{array}{c}\text { Tipo de } \\
\text { Produção }\end{array}$ \\
\hline 19 & 2012 & $\begin{array}{c}\text { J. Bras. } \\
\text { Psiquiatr. }\end{array}$ & $\begin{array}{r}\text { Análise da percepção da fadiga, } \\
\text { estresse e ansiedade em } \\
\text { trabalhadores de uma indústria de } \\
\text { calçados }\end{array}$ & Artigo \\
\hline 20 & 2010 & $\begin{array}{c}\text { Revista } \\
\text { Perspectiva } \\
\text { Online }\end{array}$ & $\begin{array}{r}\text { Impactos gerados pelo trabalho em } \\
\text { turnos }\end{array}$ & Artigo \\
\hline 21 & 2007 & $\begin{array}{c}\text { Rev. Enferm. } \\
\text { UERJ }\end{array}$ & $\begin{array}{c}\text { Percepção da Duração do Sono e da } \\
\text { Fadiga entre Trabalhadores de } \\
\text { Enfermagem }\end{array}$ & Artigo \\
\hline 22 & 2008 & $\begin{array}{c}\text { J. Bras. } \\
\text { Pneumol. }\end{array}$ & $\begin{array}{c}\text { Diagnósticos dos transtornos do sono } \\
\text { relacionados ao ritmo circadiano }\end{array}$ & Artigo \\
\hline
\end{tabular}

A análise dos dados foi realizada baseada nos artigos selecionados, em que foi possível observar, contar e somar, descrever e qualificar os dados, para aglomerar o conhecimento produzido através da temática nessa revisão, tanto que na sexta etapa demonstrou-se a revisão e síntese do conhecimento que foi visto em artigos analisados ${ }^{4}$.

\section{TRABALHO NOTURNO FRENTE ÀS DOENÇAS OCUPACIONAIS E A QUALIDADE DE VIDA DOS PROFISSIONAIS DE ENFERMAGEM}

Categoria: As consequências ocupacionais do trabalho noturno e a qualidade de vida dos profissionais de Enfermagem

O adicional noturno é amparado por lei, conforme a Consolidação das Leis do Trabalho (CLT), que prevê no artigo 73 que o trabalho executado entre as 22 horas de um dia e as 05 horas do dia seguinte é considerado noturno, sendo remunerado com adicional de $20 \%$. Porém este turno pode oferecer qualidade de vida ou riscos ocupacionais por consequências a partir dos objetivos do profissional, em que muitos trabalham a noite para ter um aumento na renda ${ }^{7,8}$.

Desde 1920 vários autores têm discutido a privação aguda e crônica de sono, privações totais ou seletivas e avaliações do desempenho pós-privação, mas alguns instrumentos de análise foram diferenciados, produzindo resultados contraditórios e 


\section{Atenção à Saúde}

concordância entre vários pontos, na maioria dos casos o trabalhador em vez de descansar parte para outras atividades laborais ${ }^{8,9}$.

Devido às crescentes mudanças econômicas, demográficas e nos processos tecnológicos, havendo a necessidade de uma sociedade cujos serviços funcionem em 24 horas, sete dias por semana, que depende de um grande número de profissionais durante noites ininterruptas, surge a necessidade de manter um padrão de vida em que a maioria dos salários baixos a que os profissionais de enfermagem se submetem faz com que haja mais de um emprego, tendo assim impacto negativo na vida social, familiar e laboral 8,10 .

Para que a jornada semanal seja cumprida, parece bastante razoável supor que, pelo menos no caso dos trabalhadores de enfermagem, o serviço seja exercido além do horário diurno, viabilizando as vinte e quatro horas à beira do leito ${ }^{9,11}$.

Há, portanto, uma parcela da população economicamente ativa que, além de trabalhar acima das horas previstas em lei, ainda o faz em horário noturno, para complementar a renda ou por necessidade para atividades diurnas; assim, não há, portanto, como negar a existência de uma sociedade 24 horas, a qual depende de vasto número de trabalhadores, que estão sujeitos à exposição de fatores psicossociais do trabalho que interferem nos processos saúde-doença, não apenas por trabalhar à noite e sim pela falta de descanso por vários motivos ${ }^{1,9,10,11,12}$.

O trabalho em turnos, diurno e noturno, é considerado um relevante agravo à saúde, levando à fadiga, ao débito agudo e crônico de sono e a várias outras doenças, a partir do momento que o trabalhador tenha mais de um emprego, baixa remuneração, atividades diárias como o cuidado da família ou estudos ${ }^{1,12,13}$.

Dessa forma, o serviço noturno pode acarretar problemas para o funcionário participar de atividades ou responsabilidades familiares importantes, tais como o papel de companheiro social e conjugal, na realização das refeições em família, divisão de tarefas domésticas, acompanhamento do progresso acadêmico dos filhos, participação de reuniões escolares e no cuidado da manutenção da casa. Interferindo nesses setores o trabalhador fica suscetível às doenças ocupacionais ${ }^{8,9,14}$.

As condições de trabalho e a organização do trabalho influenciam de forma significativa a tolerância ao trabalho nos turnos diurno e noturno. Particularmente, trabalhar em horários não diurnos pode levar os trabalhadores a ter pior desempenho em suas tarefas, a expô-los a maiores riscos de acidentes de trabalho, de forma mais 


\section{Atenção à Saúde}

acentuada, a estressores ambientais, que podem levá-los à incapacidade funcional precoce $^{1,10,12,13}$.

Os trabalhadores noturnos podem ter hábitos alimentares alterados, em que muitos optam por energéticos, cafeína e estimulantes, cujo consumo excessivo é prejudicial à saúde e ao término do efeito o organismo perde a noção de sono e dorme sem perceber, perdendo totalmente o autocontrole $e^{8,9,14}$.

Alguns consomem mais alimentos gordurosos, pré-cozidos, congelados, o que influencia no ganho ponderal, aumento do colesterol, constipação, flatulência, gastrite e úlcera, impactando diretamente na saúde e qualidade de vida ${ }^{15,16}$.

É importante frisar que para a qualidade de vida do trabalhador há necessidade de consumir alimentos mais leves durante os plantões noturnos, diminuir o açúcar e alimentos fritos, restringir o café e realizar atividades físicas de maneira sistemática, no intuito de minimizar os reflexos do trabalho em sua saúde, tanto que podemos sugerir exercício laboral antes de iniciar o plantão ou no final, além do jantar no refeitório laboral, um lanche noturno oferecido pelo empregador ${ }^{7,8,10}$.

Alguns profissionais, para estarem acordados, utilizam medicamentos, o que pode ocasionar alguns sintomas, tais como: insônia, Sonolência Diurna Excessiva (SDE), risco para enfermidades cardiovasculares, gastrintestinais, infertilidade e até o déficit de atenção, o que pode, além do risco à segurança do trabalhador, comprometer também a segurança do paciente, no caso da Enfermagem²,17.

Mas, o descanso físico proporcionado pelo sono é fundamental para o bom desempenho das atividades laborais, tendo aqui um conflito histórico: de um lado, a satisfação às necessidades econômicas e técnicas, de outro, as necessidades humanas básicas do trabalhador. Mas a Lei Estadual no 6.296/2012, "Lei do Descanso" para os profissionais da Enfermagem, em vigor no Estado do Rio de Janeiro, tem a possibilidade de ser posta nacionalmente pelo Projeto de Lei do Senado no 597, em tramite desde 2015 17,18,19,20.

Um estudo com indivíduos de várias áreas que trabalhavam em períodos de seis dias no turno noturno evidenciou a má adaptação do ciclo circadiano endógeno por alterações abruptas nos turnos associada ao metabolismo. Com o descanso no período de trabalho há uma diminuição desses efeitos, para assim manter a qualidade de vida do trabalhador $9,17,20$. 
O sono curto apresenta uma correlação com sobrepeso e obesidade, o que mostra uma relação inversamente proporcional entre peso e horas dormidas/dia. Dados preliminares apontam diversas consequências neuro-humorais de restrição de sono, como alterações do balanço simpático-vagal, aumento de cortisol, redução dos pulsos de secreção do hormônio do crescimento e dos níveis plasmáticos de leptina, substância que regula o apetite e o gasto de energia; por isso a necessidade do horário de descanso no plantão e após $7,8,19,20$.

Em um estudo, as autoras reforçam que o ganho ponderal referido por enfermeiros mostra os relatos dos maus hábitos alimentares, ao lanche coletivo, utilizado como estratégia para inibir o sono, que também pode ser uma das consequências da impossibilidade da prática de atividade física, principalmente no dia posterior ao plantão, indicando a relação com a influência do sono e do cansaço/desgaste físico e mental do trabalhador de Enfermagem, na qual há necessidade de incentivo de atividade física e até mesmo de ginástica laboral como forma preventiva do estresse ${ }^{8}$.

Assim, para informação, destaca-se a divisão do sono em cinco fases: na primeira, ocorre o adormecimento; na segunda, a temperatura corporal e os ritmos cardíacos diminuem, assim como as ondas cerebrais; na terceira, o corpo começa a entrar em um sono profundo; já na quarta, o sono é profundo, fazendo com que a pessoa se recupere do cansaço diário; mas, na quinta fase, conhecida como sono REM, a atividade está em plena ação e desencadeia o processo de formação de sonhos, a frequência cardíaca e respiratória voltam a aumentar, os músculos ficam paralisados e a pressão arterial sobe, nessa fase o cérebro fixa as informações captadas durante o dia, mas descarta as menos importantes ${ }^{2,21}$.

Desta forma, quando o trabalhador noturno passa a tentar dormir de dia, leva o organismo à dessincronização interna, sente-se alerta, mas na realidade precisa repousar no momento em que o corpo se prepara para a vigília, levando a queixas relativas a problemas de sono comuns entre trabalhadores sob escalas de plantão $0^{9,11,19,20 .}$.

O estresse laboral é um fenômeno subjetivo, que se expressa no reconhecimento a respeito de inabilidade de lidar com as demandas das situações de trabalho, produzindo uma série de consequências onerosas e debilitantes que afetam os trabalhadores em vários aspectos psicossociais e organizacionais do trabalho, 


\section{Atenção à Saúde}

associados com uma variedade de efeitos adversos à saúde, como problemas cardiovasculares, transtornos mentais, lesões musculoesqueléticas e fadiga. Por isso a "Lei do Descanso", que já foi implementada no Rio de Janeiro, precisa ter o âmbito nacional, como também a aprovação do piso nacional e as 30 horas, lutas essas que melhorariam a qualidade de vida dos profissionais ${ }^{2,19,20,21}$.

Ao reforçar a implementação dessas leis, diminuiriam os transtornos relacionados com o ritmo circadiano, que se caracterizam pelo desalinhamento entre o período do sono, ambiente físico e social nas 24 horas, pois como a luz é o principal sinal para sincronizar os relógios biológicos, pessoas cegas e trabalhadores em turnos e noturnos são mais propensos a desenvolver transtornos do sono ${ }^{17,18,22}$.

Também resolveria os problemas sociais vividos pelos trabalhadores em turnos, particularmente à noite, pelo cotidiano diferenciado da comunidade, como a distribuição temporal das atividades diárias, tendo como reflexo os efeitos neurofisiológicos na diminuição do nível de vigilância; do desempenho, nas tarefas que requerem atenção e concentração; e psicológicos, com o aumento na incidência de irritabilidade e condutas anti-sociais $8,10,11,23$.

Essas condutas antissociais podem levar ao isolamento social, que se traduz nas dificuldades do conviver entre familiares, como no relacionamento conjugal, pai/mãe, filho/a ou parente e aos amigos, clubes e atividades religiosas. Essa falta de sociabilidade é proveniente da sobrecarga de trabalho, o que obriga o profissional de enfermagem a ter estratégias para lidar melhor com os turnos e a demanda social ${ }^{8,10}$.

Um fator de risco para a equipe de Enfermagem é a remuneração baixa, o que implica a submissão de outros empregos em diferentes turnos de trabalho, aumentando a jornada de trabalho de 40 horas para 80 ou mais horas, na tentativa de melhorar seus rendimentos, o que possibilita a exposição de riscos para o profissional e a clientela, pois ao acontecer uma situação iatrogênica, o trabalhador é penalizado e nada muda diante deste problema ${ }^{3,23,24}$.

Foi percebido durante o estudo que os trabalhadores sofrem agravos variados que envolvem a esfera física e mental, pertinentes às tarefas que executam rotineiramente, portanto, apesar do caráter altruísta da profissão de enfermagem, as atividades estão cercadas por aparos de leis, reconhecida como profissão, que sugere responsabilidade ética e bioética do profissional, que fica durante o exercício exposto a riscos eminentes, não tendo os direitos reconhecidos ${ }^{2,9,21}$. 
A realidade cotidiana dos trabalhadores de Enfermagem se resume às longas jornadas de serviço, à precarização das relações existentes, à desvalorização do salário, às péssimas condições oferecidas pelo empregador, que contribuem para o desgaste físico e emocional, cujas exigências são tão expressivas que afasta 0 enfermeiro da assistência, obrigando a delegar as ações para a equipe, infelizmente ${ }^{9,14,23}$.

Reforça-se, ainda, que o trabalho noturno é primordial para a continuidade da assistência. Porém na discussão foi observada a necessidade de reflexões sobre os dados encontrados nos estudos do profissional de Enfermagem que realiza plantões noturnos. Na maioria das unidades de saúde, principalmente da rede privada, as repercussões da fadiga pela alternância do ciclo vigília-sono e a diminuição do estado de alerta, dificuldade de concentração, permitem a vulnerabilidade à ocorrência de erros e acidentes de trabalho $0^{8,16,22}$.

Frente a todas estas questões, cabe ressaltar que os trabalhadores de Enfermagem em sua maioria são do sexo feminino, sendo que o grande número exerce as atividades no horário noturno, para cuidar das atividades da residência e dos filhos, formando um ciclo interrupto nas 24 horas $3,21,23$.

Os pontos supracitados nos remetem, novamente, às lutas dos profissionais de Enfermagem pelo Conselho Federal de Enfermagem e Federação dos Enfermeiros, ao se posicionarem na reivindicação, no território nacional, pelo piso salarial, carga horária semanal de 30 horas, no caso da lei estadual do descanso, que já está em tramites para estender a todo país, para diminuir a exposição dos riscos de acidentes e isolamento social $3,19,20,21,24$.

O plantão noturno é necessário, porém nas instituições de saúde a adequação do ambiente é importante, além de quantitativo de pessoal de Enfermagem compatível, material de qualidade e espaço para descanso e relaxamento, uma vez que lidamos com indivíduos no processo saúde doença, em um momento frágil, no qual muitas vezes ocorre o risco eminente de morte ${ }^{7,819,20}$.

Vale salientar a necessidade de mudança na lei do adicional noturno, para a equipe de saúde, em especial a Enfermagem, que atualmente versa de 22:00 a 05:00 horas da manhã, sendo que o turno da noite acontece das 19:00 as 07:00 horas do dia seguinte. Essa situação é desrespeitosa e promove a desvalorização do 


\section{Atenção à Saúde}

profissional de Enfermagem, que é exigido ao extremo, pois o cuidado é marcado pela responsabilidade nas ações e condutas ${ }^{1,12}$.

Essa abordagem não esgota este assunto, pois são necessários mais estudos para reflexões e uma postura política dos profissionais de Enfermagem, não política partidária e sim a reivindicação dos direitos através das entidades de classe da profissão Enfermagem, cujo principal objetivo é cuidar. A saúde ocupacional é uma importante estratégia, não apenas para garantir a saúde dos trabalhadores de Enfermagem, mas para contribuir com a motivação, satisfação no trabalho, produtividade, para a melhoria geral na qualidade de vida dos indivíduos enfermos no ambiente hospitalar ${ }^{12,10}$.

\section{CONCLUSÃO}

Através dos estudos existentes, observou-se os transtornos causados na saúde, vida social e familiar dos profissionais da saúde, no serviço noturno, ocorrendo infelizmente mais pontos negativos para o trabalhador e relacionados às condições trabalhistas.

O profissional da área de Enfermagem é visto em um paradoxo, cujo "cuidar" é inerente à sua função, porém para "cuidar" é preciso estar bem fisicamente e psicologicamente, sendo que para isso é necessário remuneração digna, carga horária de 30 horas e o cumprimento da "lei do descanso", para haver a diminuição da dupla jornada, situações iatrogênicas, na qual se torna culposo pela falta de estrutura.

Ao lidar com vidas humanas o profissional deve estar atento a todas as situações, que envolve os procedimentos diretos e indiretos na clientela, porém os estudos não têm mostrado as devidas condições no ambiente laboral, qualidade do material de insumo, quantitativo de pessoal e remuneração, favorecendo ao desgaste físico e mental, aumentando os riscos de acidentes de trabalho e, o mais grave, risco para as pessoas assistidas.

As instituições deveriam ter a preocupação com a saúde dos funcionários, criando lugares para o descanso, propiciando que o serviço seja executado com prazer e não visto como "sofrimento ou angústia", pelo profissional pensar que é menos importante do que os clientes e observar outros profissionais sendo 


\section{Atenção à Saúde}

supervalorizados. É importante ressaltar que na equipe multidisciplinar a Enfermagem promove a assistência direta ao ser humano em sua essência nas 24 horas ininterruptas, prevenindo infecções, medicando e realizando os cuidados gerais.

Os estudos mostraram a preocupação em estar descansado para realizar o trabalho de maneira segura e no dia seguinte conseguir realizar as tarefas do cotidiano. Porém vários artigos evidenciam que na prática as dificuldades são inúmeras, pois o organismo luta contra o sono por causa da natureza diurna, com a noite para repousar e repor as energias; com a Lei do Descanso, alguns problemas são diminuídos e favorecem uma melhor qualidade de vida.

Ao ratificar que o profissional noturno tem direito ao descanso, mas não há um lugar adequado para gozar desse direito, observa-se um problema, sendo necessário o posicionamento das entidades de classe da área da Enfermagem, principalmente do sindicato, pois se sabe que a prevenção de doenças e de acidentes é também fruto de um ambiente laboral saudável e seguro. Se o sono dos profissionais não é respeitado, o cuidado fica comprometido, o que acaba oferecendo riscos vitais à clientela.

Com o olhar na Enfermagem do trabalho seria necessária a presença deste nas instituições de saúde, não só para avaliação periódica, mas para definir limites entre o que é necessário na empresa, analisando estresse e outros distúrbios decorrentes do serviço noturno e até do diurno, podendo realizar estratégias para diminuição da carga mental e psíquica, como o risco de adoecimento mental e emocional, bem como a implementação da ginástica laboral.

Cabe à Enfermagem está sempre alerta e unida para que as condições de serviço sejam as melhores possíveis, por lidar com vidas no momento mais frágil, e para conseguir trabalhar de forma organizada, administrando o tempo para a realização das tarefas com menos agravos possíveis à saúde do trabalhador.

Contudo temos deveres, mas é primordial que os direitos sejam preservados, leis e resoluções adequadas para os profissionais, para que assim os reflexos do serviço noturno sejam positivos e favoráveis para o devido respeito da profissão, família e vida social. 


\section{REFERÊNCIAS}

1. Fischer FM, Moreno CRC, Rotemberg L. Trabalho em Turnos e Noturno: Na Sociedade 24 Horas. Atheneu Rio. 2003.

2. Maynardes DCD, Sarquis LMM, Kirchhof ALC. Trabalho noturno e morbidades de trabalhadores de enfermagem. Cogitare Enferm. Curitiba. 2009;14(4):703-08.

3. Silva MB, Fontana RT, Almeida MA. Diagnósticos de enfermagem na saúde do trabalhador: estudo de caso com profissionais de enfermagem. Rev Pesqui Cuid Fundam. (Online). 2012;4(4):2930-41.

4. Souza MT, Silva MD, Carvalho R. Revisão integrativa: o que é e como fazer. Einstein 2010;8(1 Pt 1):102-06.

5. Mendes KDS, Silveira RCCP, Galvão CM. Revisão Integrativa: método de pesquisa para incorporação de evidências na saúde e na enfermagem. Texto Contexto Enf., Florianópolis, 2008;17(4):758-764.

6. Minayo MCS. O desafio do conhecimento: pesquisa qualitativa em saúde. 12a ed. São Paulo: Hucitec, 2010.

7. Medeiros SM, Macêdo MLAF, Oliveira JSA, Ribeiro LM. Possibilidades e limites da recuperação do sono de trabalhadores de enfermagem. Rev Gaúcha de Enfermagem 2009;30(1):92-8.

8. Silva RM, Beck CLC, Magnago TSBS, Carmagnani MIS, Tavares JP, Prestes FC. Trabalho noturno e a repercussão na saúde dos enfermeiros. Esc Anna Nery (Online). 2011;15(2):270-6.

9. Silva RM, Beck CLC, Zeitoune RCG, Prestes FC, Tavares JP, Guerra ST. Sentido do trabalho para enfermeiros noturnos de um Hospital Universitário: estudo descritivo. Online Braz J Nurs. (Online). 2011;10(3):[12 telas]. 
10. Barboza JIRA, Moraes EL, Pereira EA, Reimão RNAA. Avaliação do padrão do sono dos profissionais de enfermagem dos plantões noturnos em Unidade de Terapia Intensiva. São Paulo Einstein. 2008;6(3): 296-301.

11. Rotenberg L, Portela LF, Marcondes WB, Moreno C, Nascimento CP. Gênero e trabalho noturno: sono, cotidiano e vivências de quem troca a noite pelo dia. Cad Saúde Pública [Internet]. 2001;17(3):639-49.

12. Neves MJA, Branquinho NCSS, Paranaguá TTB, Barbosa MA, Siqueira KM. Influência do trabalho noturno na qualidade de vida do enfermeiro. Rev Enferm. UERJ, Rio de Janeiro, 2010;18(1):42-47.

13. Moreno CRC, Fischer MF, Rothenberg L. A saúde do trabalhador na sociedade 24 horas. São Paulo em Perspectiva. 2003;17(1):34-36.

14. Cia F, Barham EJ. Trabalho noturno e o novo papel paterno: uma interface difícil. Estudos de Psicologia 2008;25(2):211-21.

15. Simões MRL, Marques FC, Rocha AM. $O$ trabalho em turnos alternados e seus efeitos no cotidiano do trabalhador no beneficiamento de grãos. Rev Latino-Am Enfermagem. 2010;18(6):[07 telas].

16. Lisboa MTL, Oliveira MM, Reis LD. O trabalho noturno e a prática de enfermagem: uma percepção dos estudantes de enfermagem. Esc Anna Nery. 2006;10(3):393-8.

17. Souza JC. Sonolência diurna excessiva em trabalhadores da área de enfermagem. J Bras Psiquiatr. 2007;56(3):180-3.

18. Vieira ACB. Agravos a saúde do trabalhador da área de saúde, com ênfase nas alterações do ciclo sono-vigília, ligados ao trabalho noturno. [Monografia]. [Conselheiro Lafaiete]: Universidade Federal de Minas Gerais; 2009. 30 p. 
19. Brasil. Senado Federal. Projeto de Lei do Senado no 597, de 2015. Brasília 2015.

20. Brasil. Assembleia Legislativa do Estado do Rio de Janeiro. Lei Estadual oo 6.296/2012. Rio de Janeiro 2014.

21. Medeiros Neto CF, Almeida GA, Ramos BC, Costa SKP, Silva HPA, Sousa MBC. Análise da percepção da fadiga, estresse e ansiedade em trabalhadores de uma indústria de calçados. J Bras Psiquiatr. 2012;61(3):133-8.

22. Silva ECG, Chaffin RA, Silva Neto VC, Siqueira Júnior CL. Impactos gerados pelo trabalho em turnos. Revista Perspectiva Online 2010;4(13):65-87.

23. Santa Rosa PLF, Fisher FM, Borges FNS, Soares NS, Rotenberg L, Landsbergis P. Percepção da Duração do Sono e da Fadiga entre Trabalhadores de Enfermagem. Ver Enferm. UERJ. 2007;15(1):100-6.

24. Martinez D, Lenz MCS, Barreto LM. Diagnósticos dos transtornos do sono relacionados ao ritmo circadiano. J Bras Pneumol. 2008;34(3):173-80. 